Copyright (C) 2016 by Academic Publishing House Researcher

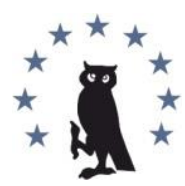

Published in the Russian Federation

European Researcher

Has been issued since 2010.

ISSN 2219-8229

E-ISSN 2224-0136

Vol. 106, Is. 5, pp. 282-292, 2016

DOI: 10.13187/er.2016.106.282

www.erjournal.ru

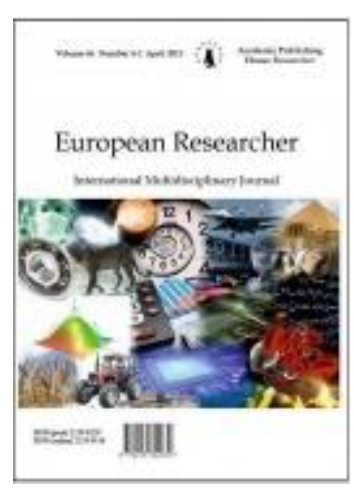

Pedagogical sciences

Педагогические науки

UDC 37

\title{
The Pedagogical Model of Innovation Technology "the Student - Tutor - Parent" as an Actual Pedagogical Problem (the Experience of the Innovative Activities of SYT in Sochi as Municipal and Regional Innovation Platform)
}

${ }^{1}$ Tatyana N. Belousova

${ }^{2}$ Anvar M. Mamadaliev

${ }^{3}$ Sergei Yu. Cheredinov

\begin{abstract}
${ }^{1}$ The department for education and science of the Sochi administration, Russian Federation $\mathrm{PhD}$

${ }^{2}$ International Network Center for Fundamental and Applied Research, Russian Federation $\mathrm{PhD}$, associate professor

3 The station of young technicians, Sochi, Russian Federation
\end{abstract}

\section{Abstract}

The article analyses the key elements of tutoring as a relevant pedagogical activity in modern social terms, and also explores the possibilities and prospects of educational technology with use of elements of tutoring, the key thesis of which is a one-time interaction of the teacher-tutor, the student and his parent within one class, the so-called bunch of "tutor - parent - student". The work substantiates the relevance of tutor support, including the scale of supplementary education institutions, identify conditions (including regulatory and legal) of successful use of tutoring technology, as well as the opportunities and risks of implementation in the sphere of additional education (on the example of the municipal budget institution of additional education the station of young technicians in Sochi city).

Keywords: tutoring activities, «tutor - parent - student», tutoring, tutorial support, educational simulation, educational technology, institution of additional education, the station of young technicians in Sochi.

\section{Введение}

В современной отечественной теории и практике все больше внимания уделяется технологиям, методам и методикам обучения и воспитания, так или иначе использующих элементы тьюторского сопровождения. При имеющихся недостатках, тьюторские технологии имеют и неоспоримые преимущества, прежде всего - очень тесная ментальная связь педагога и обучающегося. Если в образовательно-воспитательном пространстве к этой 
связке прибавить еще и родителей (то есть, обычно, наиболее авторитетных для детей лиц), то, на наш взгляд, есть шанс реализовать максимально возможный педагогический эффект.

Несколько слов следует сказать и об экспериментальной площадке - Муниципальном бюджетном учреждении дополнительного образования Станции юных техников в г.Сочи (далее - МБУДО СЮТ в г.Сочи, или СЮТ) и об одной из наиболее перспективных направлений ее работы - конструированию и робототехнике.

Первый опыт по внедрению конструирования и робототехники в образовательных организациях города Сочи показал высокую социальную востребованность данного направления и необходимость его развития, так как оно отвечает желаниям родителей видеть своего ребенка технически грамотным, общительным и умеющим найти адекватный выход в конкретной жизненной ситуации. СЮТ в 2015 году стала муниципальной, а потом и региональной инновационной площадкой для реализации соответствующих программ, основная идея которых - развитие конструирования и робототехники как на городском, так и на краевом уровне. Один из реализуемых СЮТ в г.Сочи в настоящий момент инновационных проектов, - "Развитие технического творчества детей в условиях семейной образовательной и досуговой деятельности с использованием технологии тьюторства", подчеркивается как насущной социальной потребностью, так и развивающейся вслед за этой потребностью нормативной базой, - как на федеральном (в частности, Федеральный закон от 29 декабря 2012 г. № 273-Ф3 "Об образовании в Российской Федерации", Национальная образовательная инициатива "Наша новая школа" (утв. Приказом Президента РФ от 4 февраля 2010 г. № Пр-271), концепция развития дополнительного образования детей (утв. Распоряжением Правительства РФ от 4 сентября 2014 г. № 1726-р), государственная программа Российской Федерации "Развитие образования" на 2013 - 2020 годы" (утв. Постановлением Правительства РФ от 15 апреля 2014 г. № 295), федеральные государственные образовательные стандарты), так и на региональном (в частности, Ведомственная целевая программа развития технического творчества учащихся в Краснодарском крае на 2014-2016 годы) и местном уровнях (в частности, "Муниципальная программа города Сочи "Дети Сочи" на 2014-2017 годы" (утв. Постановлением Администрации города Сочи от 29 ноября 2013 года № 2608), Приказ Управления по образованию и науке Администрации г. Сочи № 642 от 11.04.2014 "Об утверждении и реализации проекта "Развитие конструирования и образовательной робототехники в образовательном пространстве г. Сочи на период 2014-2016 гг."). Положения отечественных правовых актов всецело соотносятся с международными нормами в сфере регламентации и защиты прав детей (см., напр., Конвенция о правах ребенка).

\section{Материалы и методы}

Материалом для данной статьи послужили научные исследования по педагогике (работы М.В.Кайгородцевой [1], М.С.Коган, И.В.Хромовой, Л.В.Третьяковой [2], Е.А.Ципляевой [3], Т.М.Ковалевой [4] и др. [5]), социологии (исследования Ю.В.Васильковой [6], Л.В.Исмайловой [7], И.Ф.Дементьевой [8], Л.Я.Олиференко [9], Т.И.Шульги [10] и др.), возрастной психологии (труды Л.С.Выготского [11-12], И.С.Кона [13], Д.Б.Эльконина [14] и др.), истории педагогики (Т.Магсумов [15-17], А.А.Черкасов [18] и др., а также исследования по инновационной деятельности в педагогике (Ю.С.Тюнников [19-20] и др.)).

В данном исследовании использовались такие методы как анализ научной литературы и нормативной базы, аксиоматический, синтез, обобщение, сравнение, структурнофункциональный, педагогическое моделирование. Методология данной статьи более подробно будет освещена ниже.

\section{Обсуждение}

Как мы уже указывали в рамках другого исследования, современная система образования (в том числе - дополнительного) унаследовала многие черты советской образовательной системы, одна из которых - недостаточно эффективное взаимодействие образовательного учреждения с семьей воспитанника. Зачастую, это взаимодействие носит односторонний характер, когда образовательное учреждение (точнее - его должностное лицо) выступает только субъектом, а семья - только объектом данных отношений. Разумеется, полноценно реализовать потенциал семьи и системы образования такие 
отношения не могут. Это подтверждается и плеядой основанных на масштабных диагностических данных исследований, как педагогического (в частности, монографии М.В.Кайгородцевой, Е.А.Ципляевой, Т.М.Ковалевой и др.), так и социологического характера (например, исследования Л.В.Исмайловой, И.Ф.Дементьевой и др.). В этой связи, нами и творческим активом СЮТ был разработан инновационный проект, реализующий Концепцию развития дополнительного образования детей (распоряжение Правительства Российской Федерации от 4 сентября 2014 г. № 1726-р) и направленный на воплощение в жизнь миссии дополнительного образования как социокультурной практики развития мотивации подрастающих поколений к познанию, творчеству, труду и спорту, превращение феномена дополнительного образования в подлинный системный интегратор открытого вариативного образования, обеспечивающего конкурентоспособность личности, общества и государства. Проект, на наш взгляд, сможет также вооружить станцию значительным количеством методических инструментов для сотрудничества с другими образовательными организациями и семьями обучающихся; он рассчитан на разновозрастную категорию детей младшего, среднего и старшего и дошкольного возраста совместно с их родителями. Проект призван поддержать инновационные тьюторские технологии в области развития технического творчества детей в условиях семейной образовательной и досуговой деятельности, возникшую в педагогической среде города Сочи; направлен на дальнейшее широкое внедрение тьюторских образовательных программ в области робототехники, информатики и программирования, технологии, определяет основные направления, первоочередные меры и специфику развития технического творчества и проектной деятельности в образовательных учреждениях г. Сочи разного типа. В настоящее время, реализованная в условиях учреждений дополнительного образования и решающая указанные задачи комплексная модель тьюторской работы при единовременном взаимодействии семьи и других образовательных организаций отсутствует. В целом же можно отметить, что реализация проекта позволит Станции юных техников г.Сочи на качественно новом уровне осуществлять образовательную деятельность; он способен претворить в жизнь связку «тьютор - родитель - обучающийся» и доказать либо опровергнуть ее эффективность.

\section{Результаты}

Созданный нами и коллективом СЮТ проект "Развитие технического творчества детей в условиях семейной образовательной и досуговой деятельности с использованием технологии тьюторства", созданный в рамках муниципального конкурса "Инновационный поиск-2015", ключевым продуктом которого стала модель технологии "тьютор - родитель обучающийся", построен с использованием:

исследования);

- комплексного подхода (всесторонность и системность педагогического

- деятельностного подхода (только через деятельность и ее результаты может быть положительно или отрицательно оценен эффект внедрения проекта);

- антропологического подхода (разрабатываемые в рамках проекта учебнометодические инструменты учитывает индивидуальные особенности обучающихся и построены на принципах гуманизма).

В основу проекта легли основные научно-педагогические принципы:

- объективности;

- единства теории и практики;

- комплексности (всесторонности и целостности изучения педагогического явления и процесса);

- системности;

- научности;

- наглядности;

- доступности;

- преемственности этапов исследования и обучения;

- индивидуального подхода к обучающемуся.

Базовые методы проекта:

а) общетеоретические: 
- анализ научной литературы и нормативной базы;

- синтез;

- обобщение;

б) эмпирические:

- педагогическое моделирование;

- устный опрос;

- беседа;

- тестирование;

- анкетирование;

- наблюдение;

б) статистические:

- методы математической обработки данных;

- методы определения корреляционной зависимости.

Разрабатываемая нами модель технологии "тьютор - родитель - обучающийся", планируемая к внедрению в СЮТ в г.Сочи, ориентирована (исходя из специфики учреждения, выступающего инновационной площадкой) прежде всего в направлении научно-технического творчества. Следовательно, базовые элементы модели образовательные программы, построенные с использованием тьюторских технологий, созданы для таких объединений СЮТ в г.Сочи как конструирование, робототехника, радиосвязь, авиа- и авто моделирование и т.п. Общая концепция модели отражена на рис.1.

С учетом общей концепции ("тьютор - родитель - обучающийся"), в программах уделяется внимание не только совместным семейным занятиям в объединениях, но и проведение совместного досуга, что выявляет открытость образовательного и воспитательного процесса, которая проявляется в следующих аспектах:

- нацеленность на взаимодействие с социально-профессиональными и культурнодосуговыми общностями взрослых и сверстников, занимающихся тем же или близким видом деятельности;

- возможность для педагогов и учащихся включать в образовательный процесс актуальные явления социокультурной реальности, опыт их проживания и рефлексии;

- благоприятные условия для генерирования и реализации общественных как детских (подростковых), так и взрослых инициатив и проектов, в том числе развития волонтерства и социального предпринимательства.

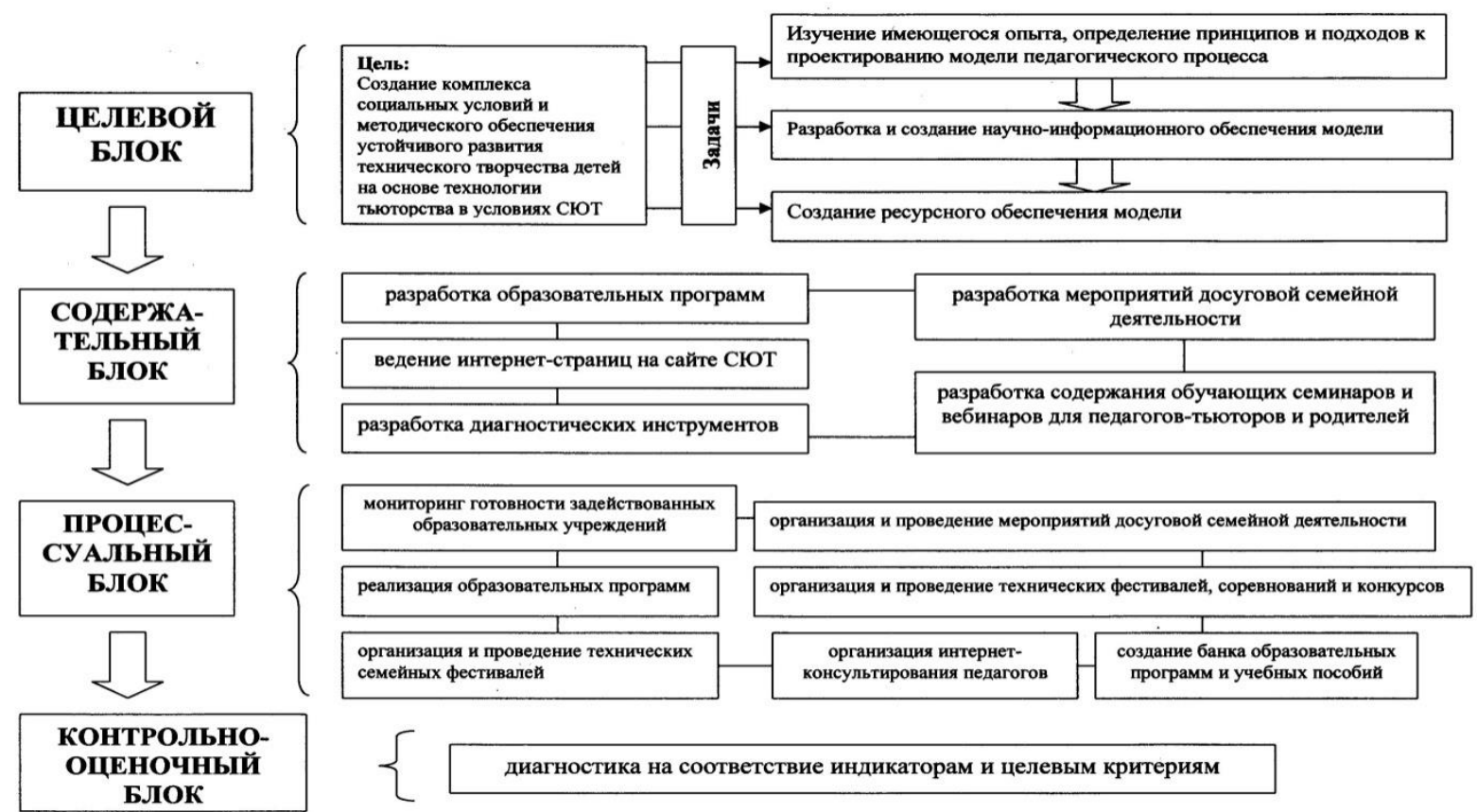

Рис. 1. Педагогическая модель деятельности МБУ ДО Станция юных техников г.Сочи (с использованием технологии тьюторства) 
Нельзя не отметить и еще один немаловажный момент: разработанная и реализованная в процессе осуществления данного проекта модель может быть внедрена без кардинальных переделок и в других учреждениях дополнительного образования технической направленности Краснодарского края.

Схематически алгоритм учебного процесса, заложенный в рабочих учебных программах, созданных в рамках проекта "Развитие технического творчества детей в условиях семейной образовательной и досуговой деятельности $\mathrm{c}$ использованием технологии тьюторства", можно изобразить следующим образом (см. рис.2).

Поясним указанную схему. Весь учебный курс включает в себя девять модулей (в сущности - самостоятельных учебных программ); обучающийся осваивает только те, которые соответствуют его личным способностям и интересам. Учебный курс предусматривает три уровня сложности - ознакомительный, базовый и углубленный. В зависимости от успехов, обучающийся может в пределах одного уровня изменить/усложнить специфику обучения. Предусмотрены три спецификации в пределах одного курса - образовательная (наименее сложная), соревновательная (более сложная, преимущественно с практической направленностью - т.е. создание модели для участия в соревнованиях) и проектно-исследовательская (наиболее сложная спецификация курса, преимущественно с теоретической направленностью - т.е. создание исследовательских проектов для участия в конкурсах различного уровня).

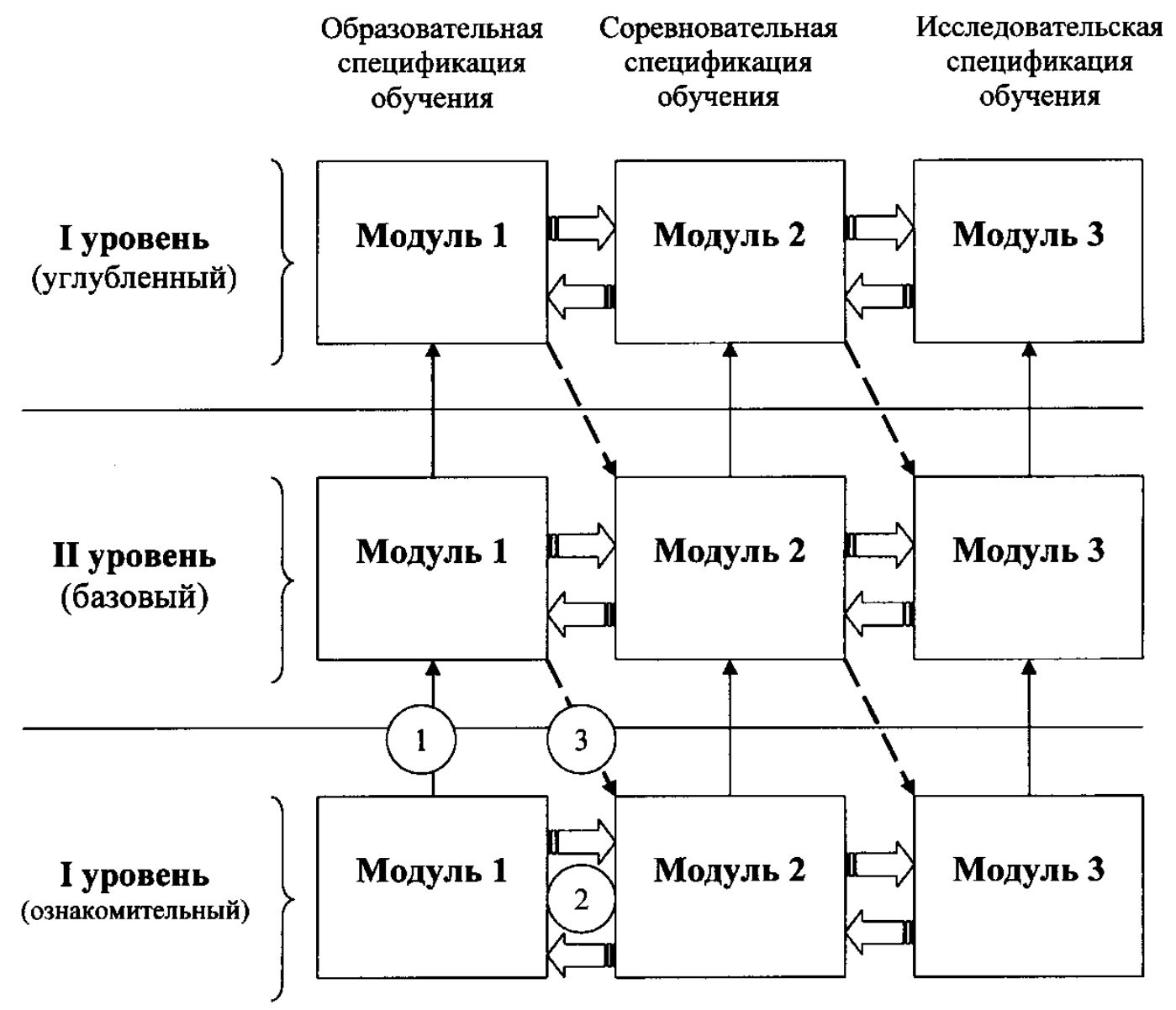

Рис. 2. Алгоритм учебного процесса с использованием технологии "тьютор - родитель обучающийся", разработанный в рамках проекта "Развитие технического творчества детей в условиях семейной образовательной и досуговой деятельности с использованием технологии тьюторства" 
Несколько слов скажем о спецификациях обучения.

1) Образовательная спецификация представляет собой основной и наиболее простой подуровень курса. Она включает основные теоретические знания и ориентирована, прежде всего, на улучшение успеваемости в рамках основного образования - школьного. Знания подаются более углубленно и в большем объеме, что позволяет говорить об о некотором опережении школьной программы особенно на высшем, углубленном уровне обучения. Если цель родителя и ребенка - улучшение успеваемости в школе, то данная спецификация - оптимальный выбор.

2) Соревновательная спецификация более «заточена» под практическую деятельность. Безусловно, она включает базовые элементы, однако направлена не на углубление теоретических знаний школьного курса, а на участие в соревнованиях с моделью, сконструированной в совместной деятельности с тьютором и родителем. Если у ребенка «золотые руки», если у него есть страсть к моделизму (конструированию) и он желает проверить свои силы в состязаниях с себе подобными - соревновательная спецификация его оптимальный выбор.

3) Исследовательская спецификация предусматривает научно-проектную деятельность и участие в исследовательских конкурсах, фестивалях, конференциях и пр.; ориентирована на ребят, имеющих склонность к научному миропониманию и соответствующий психофизиологический (в основном - интеллектуальный) потенциал. Является наиболее сложной в сравнении с двумя предыдущими, так как предусматривает в себе элементы как первой, так и второй. Например, если обучающийся выступает с инновационной модельюпроектом (исследовательская спецификация), то элементарными навыками конструирования (соревновательная спецификация) он должен обладать.

Bсе три спецификации так или иначе «работают» на достижение главной цели социализации - «создание» личности, «полезной» для общества; они также могут косвенно отражать и будущую деятельность подопечного. Образовательная подготовит «базу» будущему педагогу (воспитателю, учителю, преподавателю, тьютору), соревновательная конструктору (инженеру), исследовательская - ученому.

Рассмотрим более подробно организацию учебно-воспитательного процесса по данной схеме на примере курса «Робототехника» в СЮТ г.Сочи.

Ознакомительный уровень является наиболее легким в освоении. Его основная задача - заинтересовать ребят.

При наличии заинтересованности и психофизиологических возможностей для освоения более сложного курса, программа может быть усложнена и обучающийся, соответственно, может выбрать два варианта:

1) усложнить ознакомительный (начальный) уровень до базового (основного) в пределах образовательной специфики, т.е. углубить и расширить уровень получаемых знаний, другими словами - усложнить программу обучения только в пределах получения теоретических знаний (стрелка 1 на рис.2).

2) изменить спецификацию курса обучения на соревновательную - с практическим уклоном (стрелка 2 на рис.2). Он включает в себя разработку и конструирование роботов, изготовление работоспособных моделей или макетов, при желании - участвовать в соревнованиях. Соревновательной данная спецификация называется потому, что именно достижения в состязаниях являются вершиной проявления мастерства в практическом освоении курса обучения и, соответственно, подтверждением получения требуемых знаний, умений и навыков. Практика работы в конструкторских направлениях (робототехника, авиа, судо- и автомоделирование и др.) показывает, что не все ребята изначально желают участвовать в соревнованиях, что, как правило, объясняется неуверенностью в собственных силах. Однако по мере освоения необходимых умений и навыков, появляется и качество результата; подопечные не могут не видеть так называемую разницу «до» и «после» и уже сами начинают просить педагога предоставить им возможность участвовать в состязаниях.

Вместе с тем, у обучающегося всегда есть возможность «вернуться назад» к прежней спецификации (стрелка 2 на рис.2), если по каким-то причинам новая спецификация ему не понравилась. Как правило, существует только две группы причин «возвращения»:

а) утрата интереса, либо 
б) отсутствие необходимых психофизиологических возможностей (прежде всего усидчивости и развитой моторики рук, следствием чего и является низкий результат, что в итоге также весьма быстро приводит к утрате интереса).

Теоретически, при наличии у обучающегося сугубо научного склада мышления, он способен перейти от образовательной сразу к исследовательской спецификации; в любом случае, в нашем учреждении мы такую возможность предоставляем всегда. Другое дело, что без практических навыков конструирования (по крайней мере, применительно к курсу «Робототехника»), ему очень тяжело выдавать качественный результат, т.к. чтобы программировать, конструировать и отлаживать технику, так или иначе нужны соответствующие умения и навыки. Вместе с тем, в нашей практике были случаи, когда ребенок, будучи от природы великолепным «генератором идей», прекрасно «осваивался» в «исследовательской» группе обучающихся без обучения в «соревновательной» и показывал достойные результаты в групповой работе, постепенно осваивая «недостающие» конструкторские умения и навыки. Но данный случай является скорее исключением...

Есть также возможность "облегчить" уровень, но со сменой спецификации (стрелка 3 рис.2). Если ребенку тяжело осваивать, к примеру, теоретические знания на базовом уровне (образовательная спецификация, уровень II, модуль 1), но он с успехом освоил соответствующий модуль на ознакомительном (I-м) уровне, он всегда может попробовать применить уже полученные знания на практике (моделирование, конструирование и пр.), вплоть до соревновательной деятельности, но на облегченном уровне (в данном случае соревновательная спецификация, уровень I, модуль 2). И помощь тьютора-"наставника" (и, возможно, родителя) в такой ситуации будет весьма полезной, что, собственно, и является одной из идей проектируемой нами технологии "тьютор - родитель - обучающийся".

Оценить эффективность модели данной технологии, которая в рамках муниципального проекта "Развитие технического творчества детей в условиях семейной образовательной и досуговой деятельности с использованием технологии тьюторства" будет внедрена в СЮТ г.Сочи поможет комплекс целевых критериев, в частности:

- наличие инновационных учебно-методических комплексов, реализуемых СЮТ в рамках проекта;

- количество запланированных и проведенных мастер-классов, конкурсов, фестивалей, семинаров, тематических занятий и других форм образовательной деятельности в области научно-технического творчества воспитанников;

- наличие банка образовательных программ и учебных пособий по техническому творчеству;

- наличие сети взаимодействующих в рамках проекта образовательных учреждений;

- рост активности и результативности участия школьников в научно-технических соревнованиях, выставках и фестивалях различного уровня;

- наличие коллективной монографии, описывающий проблемы, процесс и результаты внедрения данного проекта.

Индикаторами эффективности проекта в целом могут, соответсвенно, стать:

- доля обучающихся в учреждениях дошкольного, общего и дополнительного образования в возрасте от 5 до 18 лет, задействованных в проекте;

- доля родителей, реализующих вместе с тьюторами инновационные образовательные программы проекта;

- доля педагогов, ставших тьюторами и задействованных в проекте;

- доля образовательных организаций, реализующих инновационные образовательные программы проекта;

- доля участия школьников в соревнованиях различного уровня;

- доля педагогов, готовых к внедрению инновационных конструирования и робототехники в образовательный процесс;

- число вовлеченных сторон (некоммерческие организации (НКО), партнеры, местное сообщество, поставщики, органы власти и т.п.).

При анализе эффективности внедренной модели использованы традиционные диагностические средства определения эффективности инновационной деятельности. В качестве базовых методов диагностики эффективности данного продукта отметим: 
- анкетирование всех задействованных субъектов образовательно-воспитательного процесса;

- тестирование;

- наблюдение;

- беседа;

- анализ продуктов деятельности обучающихся.

В качестве основных диагностических методик выступают:

- методика изучения скрытых мотивов поведения в ситуации выбора (как обучающихся, так и родителей). Применение данной методики покажет степень фактической заинтересованности данных субъектов образовательно-воспитательного процесса участвовать (или продолжать участие) в проекте, что косвенно покажет степень эффективности внедрения инновационных учебно-методических комплексов;

- определение доминирования познавательного или игрового мотива обучающихся (применительно к детям дошкольного и младшего школьного возраста). Данная методика позволит определить эффективность обучающего компонента проекта в соответствующей возрастной категории;

- социометрические методики (позволят определить уровень комфортности и близости/доверительности отношений обучающегося (как родственных, так и коллективных в группе) на разных этапах реализации проекта; положительная динамика будет указывать на эффективность внедрения инноваций);

- методики измерения мотивации достижения (для обучающихся старшего школьного возраста). Положительная динамика указывает на эффективность работы с детьми в процессе реализации проекта;

- методики определения ценностных ориентаций. Положительная динамика указывает на эффективность воспитательного компонента проекта.

Помимо указанных, в проекте предусматривается использование и других диагностических методов и методик, прямо или косвенно отражающих эффективность внедрения разработанной в рамках проекта инновационной модели.

Основное назначение используемых диагностических методов и методик организовать оценку эффективности проекта и соответствие целевым показателям и проектным индикаторам.

В заключение отметим, что в случае успешной апробации, модель может быть внедрена в практику деятельности других учреждений дополнительного образования, а также стать базой для формирования стажировочной площадки для руководителей и методистов образовательных организаций.

\section{Выводы}

Итак, модель проектируемой нами технологии "тьютор - родитель - обучающийся" построена с учетом тесного взаимодействия с семьей и другими образовательными организациями-партнерами, а также реализации комплекса образовательных программ технической направленности. Образовательные программы как основные элементы этой модели представляются в настоящий момент весьма актуальными и составлены в соответствии с федеральным государственным образовательным стандартом дополнительного образования. Они будут снабжены обширным учебно-методическим комплексом, призванным обеспечить их успешную реализацию в тесном взаимодействии с семьей обучающегося. Новизна модели (как и всего проекта в целом) обусловлена, прежде всего, синтезом различных образовательных линий (технологической, технической, культурологической, семейных отношений, краеведческой, инновационной) в единое образовательное содержание, реализованное в виде универсальной инновационной модели, которая (при достижении положительных результатов после апробации) вполне может быть применена и в других учреждениях дополнительного образования.

Для реализации программных компонентов модели предполагается использование проектных и тьюторских образовательных технологий; темы для совместных занятий носят рекомендательный характер, предоставляя возможность каждому педагогу-тьютору исходить из конкретных условий работы с группой детей с родителями. 
Мы предполагаем, что реализация проекта не только улучшит взаимодействие между различными образовательными организациями и семьей, но и повысит открытость образовательного и воспитательного процесса. Результатом этого станет более эффективная социализация подрастающего поколения, улучшение семейной атмосферы, оптимизация взаимодействия образовательных учреждений.

Безусловно, возможны и соответствующие риски, прежде всего - отсутствие поддержки идей проекта со стороны других субъектов образовательного процесса, а также невостребованность методических разработок, осуществленных в рамках реализации модели, в связи с опасением внедрения инноваций. Возможные пути минимизации рисков нам видятся в информационной и разъяснительной деятельность руководства, методистов и педагогов СЮТ в г. Сочи о позитивных эффектах внедрения проекта, а также диагностика и демонстрация субъектам образовательного процесса положительной динамики психического и духовного развития обучающихся по новым методикам, реализуемым в рамках проекта.

\section{Примечания:}

1. Кайгородцева М.В. Методическая работа в системе доп. образования. Материалы, анализ, обобщение опыта. М., 2009.

2. Третьякова Л.В., Хромова И.В., Коган М.С. Работа с семьей в учреждениях дополнительного образования. Аукцион методических идей. М., 2008.

3. Ципляева Е.А. Модель организации досуга и творчества детей. 5-11 класс. Программа интеллектуального клуба. М., 2009.

4. Ковалева Т.М. Основы тьюторского сопровождения в общем образовании. М., 2010.

5. Проблемы тьюторской деятельности фигурируют и в современных психологических исследованиях. См., напр., Mantorova I.V., Djevathanova D.A. Features of Safety Values of Students with Different Type of Time Perspective // European Journal of Psychological Studies. 2016. Vol.(7), Is. 1. pp. 22-28.

6. Василькова Ю.В. Методики и опыт работы социального педагога. М., 2001.

7. Исмайлова Л.В. Основы семейной педагогики. Мозырь, 2008.

8. Дементьева И.Ф. Социальное самочувствие семьи // Социологические исследования. 2008. № 9. C.102-109.

9. Олиференко Л.Я. Социально-педагогическая поддержка детства. Муниципальная система. М., 2002.

10. Шульга Т.И. Работа с неблагополучной семьей. М., 2005.

11. См., напр., Выготский Л.С. Педагогическая психология. М, 1999.

12. Выготский А.С. Вопросы детской психологии. СПб., 1997.

13. Кон И.С. Ребенок и общество. М., 2008.

14. Эльконин Б.Д. Введение в психологию развития. М., 2010.

15. Магсумов Т.А. Средняя профессиональная школа позднеиммерской России в советской историографии // Современная наука: актуальные проблемы теории и практики. Серия: Гуманитарные науки. 2015. № 5-6. С. 21-27.

16. Магсумов Т.А. «О бедном учащимся замолвите слово»: коллективные формы поддержки нуждающихся учеников в позднеимперской России // Theoretical \& Applied Science. 2016. № 1 (33). C. 127-136.

17. Магсумов Т.А. Становление и развитие средней профессиональной школы в позднеимперской России: обзор современной историографии // Современные исследования социальных проблем (электронный научный журнал). 2015. № 7 (51). С. 3-40.

18. Cherkasov A.A. All-Russian primary education (1894-1917): Developmental Milestones // Social Evolution and History. 2011. № 2, vol. 10. pp. 138-149.

19. Тюнников Ю.С. Концептуальная модель подготовки будущих педагогов к инновационной деятельности (цели-содержание-технологии) // Педагогическое образование и наука. 2014. № 5. С. 52-62.

20. Tyunnikov Yu.S. Integral assessment of future teachers' professional preparation for innovative activity // European journal of contemporary education. 2013. № 3, vol.5. pp. 183-200. 


\section{References:}

1. Kaigorodtseva M.V. Metodicheskaya rabota v sisteme dop. obrazovaniya. Materialy, analiz, obobshchenie opyta. M., 2009.

2. Tret'yakova L.V., Khromova I.V., Kogan M.S. Rabota s sem'ei v uchrezhdeniyakh dopolnitel'nogo obrazovaniya. Auktsion metodicheskikh idei. M., 2008.

3. Tsiplyaeva E.A. Model' organizatsii dosuga i tvorchestva detei. 5-11 klass. Programma intellektual'nogo kluba. M., 2009.

4. Kovaleva T.M. Osnovy t'yutorskogo soprovozhdeniya v obshchem obrazovanii. M., 2010.

5. Problemy t'yutorskoi deyatel'nosti figuriruyut i v sovremennykh psikhologicheskikh issledovaniyakh. Sm., napr., Mantorova I.V., Djevathanova D.A. Features of Safety Values of Students with Different Type of Time Perspective // European Journal of Psychological Studies. 2016. Vol.(7), Is. 1. pp. 22-28.

6. Vasil'kova Yu.V. Metodiki i opyt raboty sotsial'nogo pedagoga. M., 2001.

7. Ismailova L.V. Osnovy semeinoi pedagogiki. Mozyr', 2008.

8. Dement'eva I.F. Sotsial'noe samochuvstvie sem'i // Sotsiologicheskie issledovaniya. 2008. № 9. S. 102-109.

9. Oliferenko L.Ya. Sotsial'no-pedagogicheskaya podderzhka detstva. Munitsipal'naya sistema. M., 2002.

10. Shul'ga T.I. Rabota s neblagopoluchnoi sem'ei. M., 2005.

11. Sm., napr., Vygotskii L.S. Pedagogicheskaya psikhologiya. M, 1999.

12. Vygotskii A.S. Voprosy detskoi psikhologii. SPb., 1997.

13. Kon I.S. Rebenok i obshchestvo. M., 2008.

14. El'konin B.D. Vvedenie v psikhologiyu razvitiya. M., 2010.

15. Magsumov T.A. Srednyaya professional'naya shkola pozdneimmerskoi Rossii v sovetskoi istoriografii // Sovremennaya nauka: aktual'nye problemy teorii i praktiki. Seriya: Gumanitarnye nauki. 2015. № 5-6. S. 21-27.

16. Magsumov T.A. «O bednom uchashchimsya zamolvite slovo»: kollektivnye formy podderzhki nuzhdayushchikhsya uchenikov v pozdneimperskoi Rossii // Theoretical \& Applied Science. 2016. № 1 (33). S. 127-136.

17. Magsumov T.A. Stanovlenie i razvitie srednei professional'noi shkoly v pozdneimperskoi Rossii: obzor sovremennoi istoriografii // Sovremennye issledovaniya sotsial'nykh problem (elektronnyi nauchnyi zhurnal). 2015. № 7 (51). S. 3-40.

18. Cherkasov A.A. All-Russian primary education (1894-1917): Developmental Milestones // Social Evolution and History. 2011. № 2, vol. 10. rp. 138-149.

19. Tyunnikov Yu.S. Kontseptual'naya model' podgotovki budushchikh pedagogov $\mathrm{k}$ innovatsionnoi deyatel'nosti (tseli-soderzhanie-tekhnologii) // Pedagogicheskoe obrazovanie i nauka. 2014. № 5. S. 52-62.

20. Tyunnikov Yu.S. Integral assessment of future teachers' professional preparation for innovative activity // European journal of contemporary education. 2013. № 3, vol.5. ss. 183-200.

\section{УДК 37}

\section{Педагогическая модель инновационной технологии «обучающийся - тьютор - родитель» как актуальная педагогическая проблема (опыт новаторской деятельности МБУДО СЮТ в г. Сочи как муниципальной и краевой инновационной площадки)}

\footnotetext{
${ }^{1}$ Татьяна Николаевна Белоусова

${ }^{2}$ Анвар Мирзахматови Мамадалиев

з Сергей Юрьевич Черединов
}

\footnotetext{
${ }^{1}$ Управление по образованию и науке Администрации города Сочи, Российская Федерация Кандидат педагогических наук

${ }^{2}$ Международный сетевой центр фундаментальных и прикладных исследований, Российская Федерация
} 
Кандидат педагогических наук, доцент

3 Станция юных техников г. Сочи, Российская Федерация

Аннотация. Статья анализирует ключевые элементы тьюторства как актуальной педагогической деятельности в современных социальных условиях, а также исследуются возможности и перспективы создания педагогической технологии с использованием элементов тьюторства, ключевой тезис которой - единовременное взаимодействие педагогатьютора, обучающегося и его родителя в масштабах одного занятия, так называемая связка «тьютор - родитель - обучающийся». В работе обосновывается также актуальность тьюторского сопровождения, в том числе и в масштабах учреждений дополнительного образования, выявляются условия (в том числе - и нормативно-правовые) успешного применения тьюторских технологий, а также возможности и риски внедрения в сфере дополнительного образования (на примере Муниципального бюджетного учреждения дополнительного образования Станция юных техников в г.Сочи).

Ключевые слова: тьюторская деятельность, «тьютор - родитель - обучающийся», тьюторство, тьюторское сопровождение, педагогическое моделирование, педагогическая технология, учреждение дополнительного образования, Станция юных техников в г. Сочи. 